\title{
Živa Riječ
}

\author{
Monika Bajić \\ Biblijski institut, Zagreb \\ mbajic@bizg.hr
}
UDK:27-23;27-27
Pregledni članak Primljeno: 3, 2017 Prihvaćeno: 4, 2017

\section{Sažetak}

Biblija, koja se neosporno smatra nadahnutom Božjom riječju, napisana je pod nadahnućem Svetog Duha. Čovjek je, poput zemljane posude, upotrijebljen od Svetoga Duha da zapiše otkrivenje Božje istine u Isusu Kristu. Sveto pismo su "bogoduhe" riječi upućene Crkvi i ključne su za tumačenje i ispunjavanje Božjeg telosa za stvorenje. Cilj ovoga rada jest naglasiti i istražiti kritičnu ulogu Svetog Duha u Svetom pismu. Uslijed nadahnjujuće uloge Duha, Božja riječ nije mrtvo slovo, nego životvorna riječ koja izlijeva novi život u vjernika i u Crkvu. Upravo ova povezanost Duha i slova izdvaja Sveto pismo kao živo i aktivno te prenosi željenu transformativnu dimenziju za vjernike, kao pojedince i za zajednicu vjere.

Ključne riječi: Sveto pismo, nadahnutost, Sveti Duh, Bogoduha, živa, autoritet, Biblija, prosvjetljenje.

Ideja o riječima i spisima, nastalima pod božanskim djelovanjem, ne nalazi se samo u judaizmu i kršćanstvu nego i u islamu, hinduizmu, antičkoj Grčkoj i drevnom Rimu. Pojam "nadahnutost" u kršćanskom svijetu shvaća se kao poseban utjecaj Božjeg Duha na autore biblijskih tekstova, tako da su ovi tekstovi zbilja Božja riječ i može ih se smatrati takvima. Sveto pismo Starog i Novog zavjeta koje, prema vjeri Crkve, sadrži božansko otkrivenje, posjeduje osobit karakter: nadahnuto je, tj. njegovi su autori bili pod karizmatskim utjecajem Boga ili Svetoga Duha. Ono sadrži Božju riječ koju su zapisali ljudi te koja se zbog toga razlikuje od svih drugih svjetskih književnih djela. Zato Bloesch poziva današnje teologe da "obnove para- 
doksalno jedinstvo Riječi i Duha jer jedino na temelju ovoga jedinstva Pismo može postati živo i biti transformirajući kvasac u životu Crkve. Sveto je pismo, samo po sebi, pisana Božja riječ, koja zbog svoje božanske nadahnutosti predstavlja pouzdano svjedočanstvo o istini što ju je Bog objavio u Isusu Kristu" (1994, 25).

Ovaj rad neće se samo nakratko baviti nadahnućem nego i životvornim, prosvjetljujućim i posvećujućim karakterom Svetoga pisma uslijed djelovanja Svetog Duha. Kao nadahnuta, odnosno točnije, od Boga izdahnuta Riječ, ima li Sveto pismo moć dati život? Mijenja li ono život vjernika i zajednice vjernih?

\section{Bogoduhost}

Prije nego što nastavimo razmišljati o životvornosti Svetog pisma, prvo moramo istražiti "nadahnutost", odnosno "bogoduhost" Pisma. Klasična doktrina o nadahnuću počiva na svjedočanstvu Starog i Novog zavjeta. Ideja o duhovnosti Pisma, na koju nailazimo u 2. Timoteju 3,16 i 2. Petrovoj 1,21, temelji se na Starome zavjetu. Proroci su djelovali poput alata Svetog Duha, a budući da se njihova riječ smatrala Božjom, činilo se očitim da će pisanoj predaji pripisati jednak autoritet (vidjeti Jer 25,$13 ; 36,1 ; 45,1 ; E z$ 11,5). Što su izgovorene riječi proroka bile tiše, to su pisane riječi postajale važnije (Cranford 1999, 577). U pisanom je obliku uhvaćena moć Božjeg Duha, što joj je omogućavalo da ima utjecaj u svim vremenima. Isus, Pavao, evanđelisti i rana Crkva shvaćali su Stari zavjet kao valjani Božji dokument i kao duhovnu pouku (Cranford 1999, 577). I zato, ako pisac 2. Petrove 1,19-21 izjednačuje spise i proročko nadahnuće, drži se tadašnje judaističke tradicije (Sasse 2010, 109-10).

I dok se stihovi iz 2. Petrove bave nadahnutošću Svetog pisma ${ }^{1}$ (Berkouwer 1975, 142), Poslanica Timoteju tiče se utjecaja Svetog pisma (Warfield 1999, 83940). Obje tvrdnje objedinjuju se u crkvenoj doktrini o nadahnuću: na oba mjesta Sveto pismo pripisuje se Božjoj pneumi jer ona su $\theta \varepsilon o ́ \pi v \varepsilon v \sigma \tau o \varsigma$ - bogoduha (War-

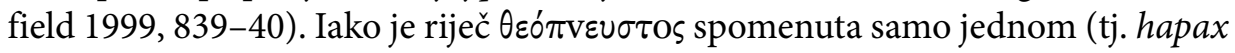
legomena) $)^{2}$ u Bibliji, ispunjava uvjete za tvrdnju o nadahnutosti (Williams 1995,

1 “Ova tvrdnja oduvijek se ticala bogoduhog karaktera Pisma. Činjenica da nam je Božja riječ došla spomenuta je u smislu podrijetla proroštva apo theou postaje dimenzija autoriteta, pouzdanosti i nepromjenjivosti. Ovo podrijetlo ne isključuje njegov ljudski karakter (ljudi su govorili), ali riječi "od Boga" pružaju ovim ljudskim riječima jedinstvenu kvalitetu pouzdanosti, koja je nužna za bogonadahnuto Pismo. Suočavanje s izdizanjem Božje riječi iz ljudskog srca jest nukanje Duha. Čvrstina ovih ljudskih riječi jest otajstvo Duha” (Berkouwer 1975, 142).

2 "Jedinstveno spominjanje riječi theopneustos u NZ jedno je od najranijih spominjanja ove riječi u grčkoj literaturi. Nekršćanski pisci koristili su se ovom riječju u 2. stoljeću, a kršćanski u 3. i 4. stoljeću" (Williams 1995, 3:171). 
3:171). Tako se Pismo naziva živom Riječju proizašlom iz Božjih usta (dah = Božja riječ). Dakle, ne postoji kontrast između žive riječi i mrtvog slova, a otkrivenje

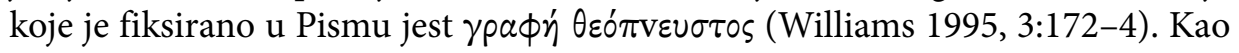
što Petrova poslanica otkriva, nema razlike u božanskom karakteru između pisane i izgovorene riječi. Obje su na istoj razini: Božji je Duh jednako sudjelovao u obje. Apostoli su rekli da su evanđelja bila "potaknuta Duhom" i da je pisana riječ proroka došla od Duha (Grenz 1994, 381-2). Berkouwer ističe povezanost Duha i slova:

Pojam "bogoduho" mnogo je vjerniji jedinstvenom djelu Svetog Duha od riječi "nadahnuće". Druga Timoteju 3,16 govori da nam je Pismo predano izdisanjem, a ne nadahnjivanjem... Tako theopneustos upućuje na suštinski odnos između Božjeg daha i graphea. Ovo je otajstvo Svetog pisma, koje Crkva želi izraziti u svojem vjeroispovijedanju. Ovo je otajstvo jedinstven karakter Svetog pisma, koji ga u svoj njegovoj ljudskosti izdvaja od svih drugih ljudskih spisa. Ljudi su jasno shvaćali da nam 2. Timoteju 3,16 ne pruža teoriju o "načinu" na koji je Pismo bogonadahnuto (1975, 139-40).

\section{Što je s "načinom"?}

O tome kako je nadahnjujuće djelo Duha točno izgledalo, osmišljene su tri glavne teorije: verbalno, osobno i stvarno nadahnuće. Verbalno je nadahnuće vjerojatno najstarija i najpoznatija teorija. Bog, odnosno njegov Duh, diktirao je Bibliju (riječ po riječ) čovjeku (vidjeti Izl 19,3-6; Br 7,89; 1 Sam 9,15) stoga je ona nepogrešiva (Böttingheimer 2016, 94-5). ${ }^{3}$ Sve do srednjeg vijeka nije bilo dvojbe ni napada na takvo "nadahnuće", o tome se u zapadnim crkvama počelo ozbiljno diskutirati nakon reformacije (Allison 2011, 59, 69). Karl Barth je za ideju o nepogrešivosti Pisma rekao da se Bog, unatoč manjkavosti ljudske riječi, poslužio njome i tako je trebamo i prihvatiti (Allison 2011, 74). Tipologija "blaga u zemljanoj posudi" (vidjeti 2 Kor 5,7) ima savršenog smisla kad je riječ o nepogrešivosti i besprijekornosti. Pismo postaje sluga stvorenjima, čije je podrijetlo zemaljsko, ali doneseno preko ljudi u formi antropomorfnog jezika. To ima smisla kad je riječ o široj slici biblijskog narativa, gdje je Bog odabirao svoje sluge kao suradnike u svojem djelovanju. "Prednost koncepcije o Pismu kao o sluzi", objašnjava John Webster, "jest njegova potvrda da stvorenjska narav teksta ne ometa njegovu ulogu u Božjem komunikativnom samoobjavljenju, tako da tekst ne mora posjedovati božanska

3 Filon Aleksandrijski ponekad je govorio o činjenici da je, primjerice, Mojsije bio obuzet Duhom ili da ga je Bog dohvatio kako bi primio riječi otkrivenja (vidjeti Filon: "De Vita Mosis" I, 250.259.263.273.275. 280). Također, Williams u svojem članku spominje da suvremena povijesna kritika odbacuje pojam diktiranja iako se i dalje govori o (doslovnom) nadahnuću, poput vjerovanja u neku vrstu diktata koje nije potpuno nestalo (1995, 162-3). 
svojstva kao zaštitu od neželjenih pojava" (Webster 2003, 24-5).

Kad govorimo o osobnom nadahnuću, smatramo da su biblijski pisci bili "nadahnuti" (tj. autori ostaju slobodni kreatori ideja sadržanih u Bibliji, dok je božanska pomoć ograničena na njihovu svrhu) (Maier 1990, 89ff). I osobno i stvarno nadahnuće ostavljaju prostora biblijskoj kritici. Govori se da je ova koncepcija postala prihvaćena u vrijeme Friedricha Schleiermachera, a sam je Schleiermacher mogao odbaciti Stari zavjet na temelju toga (tj. nadahnuta je osoba, a ne pisana riječ, tako da se Svetim pismom može rukovati na ljudski način) (Maier 1990, 89-90). Dakako, Biblija svjedoči da su ljudi bili nadahnuti od Duha, tako da se jedino postavljalo pitanje može li ova teorija opstati sama po sebi (Maier 1990, 90).

I konačno, stvarno nadahnuće znači da su značajne biblijske ideje i koncepcije nadahnute (tj. pisci nisu bili nadahnuti, kao ni njihove riječi, ali njihove misli jesu: nadahnuće je bilo ograničeno na vjerski sadržaj) (Maier 1990, 92ff). Ovakav je pristup problematičan jer tada čovjek postaje onaj koji prosuđuje o Božjoj riječi, umjesto da je obratno (vidjeti Heb 4,12). Suština je u tome da su Sveta pisma izdahnuta od Boga po njegovu Duhu, a sama metoda nije ključna za ovaj rad.

\section{Drugo mišljenje}

Na primjer, Wolfhart Pannenberg ne slaže se s klasičnom doktrinom o nadahnuću (osobito verbalnom), što potkrepljuje stihom iz 2. Timoteju 3,16. Prema njegovu mišljenju (s kojim se neki teolozi ne slažu ${ }^{4}$ ), stih govori o nadahnutim tekstovima Starog zavjeta, ne i o novozavjetnim tekstovima. Druga Timoteju 3,16 izriče svrhu Svetog pisma: "korisno je za poučavanje, uvjeravanje, popravljanje, odgajanje u pravednosti” te stih nema za svrhu potvrditi nepogrešivost Pisma (Pannenberg 1997, 2:212-3). Uslijed toga, Pannenberg smatra da postoji drugi temelj za božansko nadahnuće. Naime, sadržaj Evanđelja (tj. otajstvo) ispunjen je Duhom. Sveti je Duh osnažio službu apostola: "On nas osposobi za poslužitelje novoga Saveza, ne slova, nego Duha; jer slovo ubija, a Duh oživljuje” (2 Kor 3,6) "Svakako", Pannenberg govori, "Sveta pisma Novog zavjeta najautentičniji su do-

4 Liefeld tvrdi da prijevod grčke riječi theopneustos (bogoduho) kao "nadahnuto" u NIV Bibliji nije potpuno točan. Pojam je preširok. Grčka riječ theopneustos, koja se sastoji od theo ("Bog") i pneustos (grčki pojam koji indicira disanje) mnogo je izražajnija. Liefield nastavlja: "Potvrda o nadahnutosti u središtu ne može se odvojiti od konteksta svrhe. Pismo o kojem je riječ obuhvaća i Stari i Novi zavjet, zbog toga što se u 2. Petrovoj 3,16 Pavlovi spisi svrstavaju u Sveta pisma. U Novom zavjetu ne razlikuju se Pavlova pisma i druge knjige po pitanju njihova božanskog podrijetla i autoriteta, stoga ima smisla primijeniti 2. Timoteju 3,16 na cijelu Bibliju" (Liefeld 1999, 431, 435).

5 Ako nije drugačije naznačeno, biblijski su prijevodi uzeti iz prijevoda Jeruzalemske Biblije. 
kumenti apostolske proklamacije i nauka, stoga Pavlova tvrdnja da je Evanđelje ispunjeno Duhom opravdava zaključak da i novozavjetni spisi na neki način sudjeluju u božanskom nadahnuću" (Pannenberg 1997, 2:213).

Dalje objašnjava: "Pavlova potvrda duhovne naravi Evanđelja jest što je i samo utemeljeno u duhovnoj realnosti njegova sadržaja jer ono navješćuje Gospodina, koji je duh (2 Kor 3,17). Duhovna narav Kristova evanđelja mora se tumačiti u svjetlu Pavlove tvrdnje da je uskrsli Krist "duh koji daje život" (1 Kor 15,45)" (Pannenberg 1997, 2:213).

\section{Živa riječ ili mrtvo slovo?}

Istina je da je "Božja riječ" - Logos - postojala i prije nego što je bilo ikoga tko bi je mogao čuti ili čitati (vidjeti Otk 19,13; Iv 1,1-3; 1 Kor 8,6). Riječi Svetoga pisma (propovijedanje proroka i apostola) žive su i moćne, kao što je i vječna Riječ živa i moćna. Crkva u svojem navješćivanju Riječi "sudjeluje u životu i moći onoga koji jest Riječ". Sasse tvrdi: "Sveto pismo nikad nije mrtvo slovo" (Sasse 2010, 108-9). Kao "životvorni duh", Sveti Duh nije prestao djelovati s Pismima (vidjeti Achtemeier 1999, 123-4; Böttigheimer 2016, 73). On i danas djeluje kao što je djelovao i pri formiranju kanona. O trajnom djelovanju Duha govori se kao o prosvjetljenju, što se temelji na stihovima, kao što su Job 32,8; 1. Ivanova 5,7.11 i 1. Korinćanima 2,6-16; 2. Korinćanima 3,14-17 (Grenz 1994, 382). Djelo Svetog Duha sastoji se u prosvjetljenju ljudskih srca (umova) kako bi stupili u zajedništvo sa Svemogućim. Calvin je u komentaru o Ezekielu (2. poglavlje) rekao ovako:

Ovo djelo Duha tada se združuje s Božjom riječju. Međutim, ističe se razlika, kako bismo znali da izvanjska riječ nema moć sama po sebi ako je ne pokreće moć Duha... budući da Bog uvijek djeluje u srcima ljudi po Duhu, a njegova riječ to ne čini... moramo tako zaključiti o njegovoj riječi, jer Sveti Duh prodire u naša srca i prosvjetljuje naš razum.

Ovdje vidimo da Božja riječ nije statična, nije mrtvo slovo; Sveto je pismo živo i dinamično (vidjeti Brueggemanna 2005, 25). Još jasnije: "[Sveti Duh] čini Bibliju živom jer objašnjava Božjim vjernicima značenje biblijskih tekstova za život u sadašnjosti” (Grenz 1994, 383). Ovakvo djelo Duha, svjedočanstvo, povezuje čovjeka sa srži biblijskih tekstova, konkretno, s Isusom Kristom. Tako "vjera u božansku narav Svetog pisma 'počiva na iskustvu duhovnog života”" (Berkouwer $1975,19)$. Bog otvara ljudima "novi svijet", stvarajući nove prilike i istinsku "novinu", koju Duh stvara ni iz čega u srcima onih koji su voljni vidjeti i vjerovati. Brueggemann to definira kao "novu realnost koja se ne nudi nigdje drugdje" (1975, 8, xvi-ii). 


\section{Djelovanje Svetog pisma}

"Kad je čovjek u dodiru sa Svetim pismom", Berkouwer iznosi: "svjedočanstvo Duha otkriva mu njegovu grešnost i pokazuje mu veličanstven put oslobođenja. Ovako Duh svjedoči o Riječi jer 'Sveto pismo u božanskom sjaju počinje svjetlucati pred našim očima."' $(1975,45,19)$. Karl Barth gleda na Pismo, tj. na znanje o kršćanskoj vjeri, kao na "susret" s Bogom. Shodno tomu, stvorenja se moraju promijeniti u skladu s mjerilima strane koja se otkrila po svojim uvjetima $(1959,24)$. Barth u konačnici drži da se Bog otkrio u Isusu Kristu, a Sveto je pismo zapisano svjedočanstvo o toj istini (Grenz 1994, 392). Sveto pismo tako postaje pomagač u potrazi za theosisom (deifikacija, obogotvorenje) koji je konačni telos (konačni cilj, svrha). Websterovo je ključno opažanje da Pismo, uz to i "sredstvo milosti", ima svoje prednosti. Ova je koncepcija njezin soteriološki idiom, njezino izlaganje prirode Pisma u smislu njegova mjesta u Božjem spasonosnom ophođenju s čovječanstvom, a ne samo kao autoriteta ili epistemološke norme" (Webster 2003, 24).

Ne treba zanemariti jednu vitalnu činjenicu. Djelo Svetog Duha u vjerniku je pri vjernom čitanju i tumačenju Riječu svježe i uvijek iznova iznenađujuće. Čitatelj je tako nadahnut biblijskim tekstom da ga tumači i dalje od autorovih jasnih nakana, zamišljajući se u kontekstu riječi, što dovodi do vjere (Böttigheimer 2016, 71-2). Martin Luther (i Karl Barth) je bio uvjeren da se Božje djelo odvija putem djelovanja teksta (Böttigheimer 2016, 72). Ovako Luther obrazlaže Poslanicu Galaćanima svetog apostola Pavla:

Ljudski razum u svoj svojoj mudrosti ne može ga dovesti dalje od upućivanja ljudi da trebaju živjeti pošteno i čestito u ovome svijetu, kako da održavaju dom, grade kuće itd., što su stvari koje učimo iz filozofije i poganskih knjiga. Međutim, kako upoznati Boga i njegova dragog Sina, Krista Isusa, i kako se spasiti, tome ih samo Sveti Duh može naučiti putem Božje riječi jer filozofija ne može dokučiti božanska pitanja.

Ipak, čitanje Pisma nije uvijek nadahnuto ni prosvjetljujuće, ali i to se ipak događa, tvrdi Brueggemann. Događa se pri proučavanju, molitvi (i promišljanju) nad Pismom da osoba primi iscjeljenje, razumijevanje i vodstvo, tj. nešto "čudno i novo". Njegov je zaključak da su "slova knjige boravište i polazište vjetra koji je među nama koji svijet ne može zazvati, a Crkva mu ne može odoljeti” (2005, 33-4). Martin Buber ${ }^{6}$ sugerira da se čitatelj treba "suočiti s Knjigom svježega stava, kao s nečim novim. Mora joj se predati, ne susprezati nijedan dio svoga bića i dopustiti da se između njega i Knjige dogodi štogod se dogodi” (Buber 1968, 5 cit. u Brueggemann 2005, 17).

6 Martin Mordechai Buber (rođen 1878. u Beču, umro 1965. u Jeruzalemu) bio je austrijskoizraelski židovski religijski filozof i mislilac, politički aktivist i prosvjetni radnik. Najpoznatiji je po svojoj knjizi Ich und Du (1923.) (Ja i ti), u kojoj objašnjava razliku između "Ja - ti” i “Ja - ono" načina postojanja (Filozofija, s. v. "Martin Buber"). 
Još je jedna funkcija Pisma navedena u Ivanovu evanđelju 17,17: "Posveti ih u istini: tvoja je riječ istina." Pavao to potvrđuje u 2. Solunjanima 2,13: “... za spasenje, posvećenjem u Duhu i vjerom u istinu”. Biti posvećen znači biti učinjen svetim putem Božjeg djelovanja, a ovaj proces "posvećenja odnosi se na djelo Kristova Duha po kojem se stvorene stvari biraju, oblikuju i čuvaju kako bi mogle sudjelovati u ekonomiji spasenja: stvorenjske su realnosti posvećene božanskom upotrebom". Također, Webster tvrdi: "Posvećenje je djelovanje Duha u uređivanju povijesti stvorenja i djelujući do kraja kao ancilla Domini” (Webster 2003, 26-28).

\section{Zajednica vjere i Sveto pismo}

Mnogi teolozi i svećenici tvrdit će da je Sveto pismo plod zajedničkog rada, što i jest točno. Sveto pismo jest zajedničko djelo Duha i ljudi koji su pripadali Božjem narodu. Tako Božja riječ postaje izvor znanja i otkrivenja o Bogu, kao i o njegovu planu spasenja. Božje je djelo otkrivenja obradila zajednica vjere kako bi je ista zajednica tumačila onda i sada.

Gonzales napominje da Biblija nije napisana za privatno čitanje, nego da bi Bog putem nje govorio zajednici vjere (Gonzales 1990, 85). Isto tako, pravilno ističe da se Sveto pismo treba čitati u "vokativu, kao živa Riječ živoga Boga, koja nas ne informira prije svega o ispravnoj doktrini ni o prošlosti, nego o tome tko smo danas" (Gonzales 1990, 87). Što se sadašnjosti tiče, tekst otkriva otajstvo čitatelju (vidjeti Ef 3,1-6), tj. Crkvi, što je prvi korak prema razumijevanju i drugi korak prema cilju: prema vjernoj izvedbi božanske drame. Sveto pismo nije scenarij kojeg se moramo doslovno držati. Ono je priča čiji je cilj Crkvi razjasniti Božji konačni naum za stvorenje i pravo mjesto njegove Crkve u tome velikom eshatološkom planu. Time je obuhvaćeno i Pismo, kao norma i sudac ponašanja i postupaka Crkve. U ostvarivanju božanskog telosa Sveti Duh nastavlja nadahnjivati i udisati (novi) život u zajednicu vjere. Istodobno, Crkva svojim proživljavanjem Božje priče postaje prikaz ove "novine i čudnovatosti" svijeta Svetog pisma pred drugim stvorenjima. Riceour govori o "svijetu teksta" koji želi vjerno prodrijeti izvan Riječi u naš sadašnji svijet. Eshatološki svijet koji se probija u sadašnjost i transformira je u skladu sa svijetom teksta (Hicks 2016).

\section{Zaključne riječi}

Nadahnutost Božje riječi nikad nije bila u pitanju; uvijek se raspravljalo o načinu i dometu nadahnuća. Shodno tomu, poruka je Božje riječi istinita, svrhovita i 
ispunjena Duhom. Pod prosvjetljujućim djelovanjem Svetog Duha, Biblija ostaje naš vjerni suputnik na putu prema ostvarenju Božjeg nauma. Tako i Sin, u snazi Svetog Duha nastavlja izlijevati svoj vječni život u vjernika i u zajednicu vjere; u svoju ljubljenu nevjestu. Vjernici su tijekom povijesti, kao i danas, "u ovoj knjizi pronalazili vjetar, izvor i energiju za puninu istinskog života proživljenog bez straha" (Brueggemann 2005, 23). S velikom radošću i sigurnošću zaključujemo da se Božji nadnaravni život nastavlja putem djelovanja Svetog Duha, uz potporu Svetog pisma, koje pomaže Crkvi u vjernom tumačenju Božje drame i njezinu svakodnevnom prakticiranju. Kako je to rekao pisac Poslanice Hebrejima: "Živa je, uistinu, Riječ Božja i djelotvorna!” $(4,12)$.

\section{Literatura}

Achtermeier, Paul J. 1999. Inspiration and Authority: Nature and Function of Christian Scripture. Peabody. Hendrickson Publishers Inc.

Allison, Gregg R. 2011. Historical Theology: An Introduction to Christian Doctrine. Grand Rapids. Zondervan.

Barth, Karl. 1959. Dogmatics in Outline. New York. Harper \& Row, Publishers,

Berkouwer, G. C. 1975. Holy Scripture. Grand Rapids. William B. Eerdmans Publishing Co.

Bloesch, Donald G. 1994. Holy Scripture: Revelation, Inspiration \& Interpretation. Downers Grove. InterVarsity Press,

Böttingheimer, Christoph. 2016. Die eine Bibel und die vielen Kirchen: Die Heilige Schrift in ökumenischen Verständnis. Freiburg. Verlag Herda GmbH.

Brueggemann, Walter. 2005. The Book that Breathes New Life: Spiritual Authority and Biblical Theology. Minneapolis. Fortress Press.

Calvin, John. "Ezekiel, Part I." Calvin's Commentaries, Vol. 22. Tr. by John King, [1847-50], Internet Sacred Texts Archive. n.d. http://www.sacred-texts.com/ $\mathrm{chr} / \mathrm{calvin} / \mathrm{cc} 22 / \mathrm{cc} 22005 . \mathrm{htm}$ (pristupljeno 2. prosinca 2016.).

Cranford, Lorin L. 1999. “Inspiration.” Edited by Everett Furguson. Encyclopedia of Early Christianity. New York. Garland Publishing, Inc.

Gonzales, Justo L. 1990. Mañana - Christian Theology from a Hispanic Perspective. Nashville. Abingdon Press.

Grenz, Stanley J. 1994. Theology for the Community of God. Grand Rapids. William B. Eerdmans Publishing Company.

Hicks, John Mark. "31 Theology of Reading." Lecture Tegrity Video. Nov 16, 2016. https://lipscomb.tegrity.com/\#/recording/12f8c923-1137-46a4-940ae442ed781d3a?start Time=2209286 (pristupljeno 30. studenog 2016). 
Liefeld, Walter L. The NIV Application Commentary: 1 \& 2 Timothy, Titus. Grand Rapids: Zondervan, 1999. e-Book. https://www.scribd.com/ read/170440357/1-and-2-Timothy-Titus (pristupljeno 3. prosinca 2016.).

Luther, Martin. "St. Paul's Epistle to the Galatians - of God's Word." God's Rule. n.d. http://www.godrules.net/library/luther/NEWluther_c1.htm (pristupljeno 3. prosinca 2016.).

Maier, Gerhard. 2005. Biblische Hermenautik. Wupperthal: R. Brockhaus Verlag.

Pannenberg, Wolfhart. "Theological Table Talk: On the Inspiration of Scripture." Theology Today 54, no. 2 (July 1997): 212-215. ATLA Religion Database with ATLASerials, EBSCOhost (pristupljeno 30. studenog 2016.).

Philo, "De Vita Mosis I." Early Jewish Writings. n.d. http://www.earlyjewishwritings.com/ text/philo/book24.html (pristupljeno 23. studenog 2016.).

Sasse, Hermann. "Inspiration and Inerrancy-Some Preliminary Thoughts." Concordia Journal, 2010: 107-119. ATLA Religion Database with ATLASerials, EBSCOhost (pristupljeno 3. prosinca 2016.).

Warfield, B. B. 1999. "Inspiration." Edited by Geoffrey W. Bromiley. The International Standard Bible Encyclopedia: 839-849. William B. Eerdmans Publishing Company.

Webster, John. 2003. Holy Scripture: A Dogmatic Sketch. Cambridge: Cambridge University Press.

Williams, Joel Stephen. 1995. "Inerrancy, Inspiration, and Dictation." Restoration Quarterly 37, no. 2: 158-177.

Preveo s engleskog Davor Edelinski

Monika Bajić

The Living Word

Summary

The Bible, which is indisputable regarded as the inspired word of God, is written under the inspiration of the Holy Spirit. Man, as an earthen vessel, was used by the Holy Spirit to pen the revelation of God's truth in Jesus Christ. The Holy Scriptures are "God breathed" words to the Church and are key in interpreting 
and fulfilling God's telos for creation. This write-up wishes to emphasize and survey the critical role of the Holy Spirit in the Scriptures. Due to the inspiring role of the Spirit, the word of God is not a dead letter, rather a life-giving word that spills new life into the believer and the Church. Precisely this connection of Spirit and letter marks the Holy Scripture as living and active and conveys the desired transformative dimension for the individual believer and the faith community.

Key words: Holy Scripture, inspiration, Holy Spirit, God breathed, living, authority, Bible, illumination. 